\title{
Effect of high-frequency alternating current transcutaneous stimulation over muscle strength: a controlled pilot study
}

\author{
Diego Serrano-Muñoz ${ }^{1}$, Juan Avendaño-Coy ${ }^{2 *}$, Cristina Simón-Martínez ${ }^{1,3}$, Julian Taylor ${ }^{1}$ and Julio Gómez-Soriano ${ }^{2}$
}

\begin{abstract}
Background: High-frequency alternating currents of greater than $1 \mathrm{kHz}$ applied on peripheral nerves has been used in animal studies to produce a motor nerve block. It has been evidenced that frequencies higher than $5 \mathrm{kHz}$ are necessary to produce a complete peripheral nerve block in primates, whose nerve thickness is more similar to humans. The aim of the study was to determine the effect on muscle strength after the application of a high-frequency stimulation at 5 and $10 \mathrm{kHz}$ compared to sham stimulation in healthy volunteers.
\end{abstract}

Findings: Transcutaneous stimulation at $5 \mathrm{kHz}, 10 \mathrm{kHz}$ and sham stimulation were applied to eleven healthy volunteers over the ulnar and median nerves for $20 \mathrm{~min}$. Maximal handgrip strength was measured before, during, immediately after the intervention, and $10 \mathrm{~min}$ after the end of intervention. The $10 \mathrm{kHz}$ stimulation showed a lower handgrip strength during the intervention (28.1 N, SEM 3.9) when compared to $5 \mathrm{kHz}(31.1 \mathrm{~N}$, SEM 3.6; $p<0.001)$ and to sham stimulation (33.7 N, SEM 3.9; $p<0.001$ ). Furthermore, only stimulation at $10 \mathrm{kHz}$ decreased handgrip strength when compared to baseline.

Conclusions: These findings suggest high-frequency stimulation has an inhibitory effect over muscle strength. Future studies are required in patients that are characterized by motor hyperactive such as spasticity or tremors.

Clinical trial registration: NCT, NCT03169049. Registered on 30 May 2017

Keywords: Electric stimulation, High-frequency alternating current, Nerve conduction, Motor nerve block, Hand strength

\section{Background}

Previous studies in animals have shown that high-frequency alternating current (HFAC) of greater than $1 \mathrm{kHz}$ applied on exposed peripheral nerves can produce a motor nerve block (Bhadra and Kilgore $[1,2])$. An in vivo study, [3] showed that frequencies higher than $5 \mathrm{kHz}$ were able to block nerve conduction of motor fibers. One study [4] in non-injured subjects showed an incomplete block when transcutaneous HFAC applied to the radial nerve at $5 \mathrm{kHz}$ increased somatosensory thresholds. It has been evidenced [5] that frequencies higher than $5 \mathrm{kHz}$ are necessary to produce a complete peripheral nerve block in primates, whose nerve diameter is similar

\footnotetext{
* Correspondence: juan.avendano@uclm.es

${ }^{2}$ Toledo Physiotherapy Research Group (GIFTO), Nursing and Physiotherapy

School, Castilla La Mancha University, 45071 Toledo, Spain

Full list of author information is available at the end of the article
}

to humans, however, there is not any human study that apply HFAC transcutaneously with frequencies higher than $5 \mathrm{kHz}$. It is believed that the nerve conduction block produced by application of HFAC could be a useful tool for the treatment of patients with pain or with an exaggerated increase of nerve activity, such as hypertonia or spasms.

The purpose of this study was to determine the effects on maximal handgrip strength (MHS) of a non-invasive HFAC at $5 \mathrm{kHz}$ and $10 \mathrm{kHz}$ applied to the ulnar and median nerves in healthy subjects, compared to a sham stimulation.

\section{Methods \\ A randomized, crossover, single-blinded, placebo-controlled trial was conducted in 11 healthy volunteers after signing the informed consent approved by the Local Ethics Committee. Participants received three randomized}


(www.randomizer.org) interventions $(10 \mathrm{kHz}, 5 \mathrm{kHz}$, and sham stimulation) with a washout period of 24-h. Moreover, four measurements were registered: before $(0 \mathrm{~min})$; during the intervention at $15 \mathrm{~min}$ from onset (15 min); immediately after intervention (20 min) and $10 \mathrm{~min}$ after the intervention had finished (30 min).

All interventions were applied for 20 min with two surface self-adhesive electrodes (ValuTrode, Axelgaard Manufacturing, USA) $5 \mathrm{~cm} \times 5 \mathrm{~cm}$, which were placed on the anterior face of the dominant forearm, over the ulnar and median nerves. The proximal electrode was fixed in the path of the ulnar nerve over the epitrochlea and the distal electrode was placed on the median nerve over the carpal tunnel. A stimulator (Myomed 932. Enraf Nonius, Netherlands) delivered a sinusoidal current without modulation, at a frequency of $10 \mathrm{kHz}$. Intensity was determined by a "strong but comfortable tingle" sensation, just below motor threshold. The intensity was gradually increased until a minimally visible contraction was observed and subsequently decreased until it disappeared, and this sensation remained throughout the session. To avoid habituation to the stimulus, participant were asked every 2 minutes to corroborate the perceived sensation, and the intensity was increased if requested $[6,7]$. The same procedure was performed with the $5 \mathrm{kHz}$ stimulation. The sham stimulation session was applied by progressively increasing the intensity of a non-connected channel. Participants were also blinded to the hypothesis of the study by being informed that in some cases the perceived sensation might be different because the intensity could be adjusted to below their sensitive threshold, with the possibility that the participant may or may not feel the current $[4,8]$.

Dynamometry is a reliable and objective method to quantify manual grip strength. The absence or decrease of muscle contraction is considered as an indicator of motor nerve block [8], so dynamometry can be used as an indirect measure to assess the block of motor fibers in humans. Handgrip strength is mediated by ulnar and median nerves and was measured with a handgrip dynamometer (Grip Strength Dynamometer, Tokyo). Three repetitions were registered, and the mean was taken as a value of the average maximal strength.

Statistical analysis was performed with the software "SPSS Statistics 22.0". Due to the confirmed normal distribution of the data, a parametric test was adopted. Two-way repeated measures ANOVA (time and intervention factors) was performed with a Bonferroni post-hoc test. $p<0.05$ was considered significant.

\section{Results}

Eleven subjects (4 males, 36\%) with a mean age of 22 years (SEM 1.9) completed the study. The $10 \mathrm{kHz}$ intervention showed a greater initial and final intensity
(Initial: $23 \mathrm{~mA}$, SEM 3.3; Final: $39.9 \mathrm{~mA}$, SEM 4.0) than the $5 \mathrm{kHz}$ intervention (Initial: $13.0 \mathrm{~mA}$, SEM 1.4; Final: $21.5 \mathrm{~mA}$, SEM 2.1), $p<0.01$ and $p<0.001$, respectively. Table 1 shows data of MHS measurement of each participant. No differences were reported for maximal handgrip strength before the interventions. Significant differences in the "time" factor $\left(\mathrm{F}_{(3,8)}=4.49 ; p=0.04\right)$, the "intervention" factor $\left(\mathrm{F}_{(2,9)}=8.38 ; p=0.009\right)$ and the "time-intervention" interaction $\left(\mathrm{F}_{(6,5)}=6,08 ; p=0.03\right)$ were detected. Specifically, HFAC applied at $10 \mathrm{kHz}$ evidenced a statistically significant decrease in MHS at 15 min during the intervention (28.1 N, SEM 3.9; $p=0.001)$ when compared to baseline $(32.6 \mathrm{~N}$, SEM 4.0 ) and to $10 \mathrm{~min}$ post-stimulation (31.4 N, SEM 3.7; $p=0.02$ ). Sham stimulation and $5 \mathrm{kHz}$ interventions did not show any statistical change from baseline. Between-group comparisons showed a lower handgrip strength with $10 \mathrm{kHz}(28.1 \mathrm{~N}$, SEM 3.9) when compared to $5 \mathrm{kHz}(31.1 \mathrm{~N}$, SEM 3.6; $p=0.001)$ and to sham intervention (33.7 N, SEM 3.9; $p=0.003$ ) during the stimulation. Immediately after the intervention, a lower MSH was also found in the $10 \mathrm{kHz}$ group (29.9 N, SEM 3.7) when comparing to $5 \mathrm{kHz}(32.1 \mathrm{~N}$, SEM 3.6; $p=0.02)$ and sham stimulation $(32.2 \mathrm{~N}$, SEM 3.8; $p=0.03$ ) (Fig. 1).

\section{Discussion}

This is the first study that applies transcutaneously HFAC at $10 \mathrm{kHz}$ over a human peripheral nerve and a motor nerve conduction block is suggested evidenced by a decrease of MSH. Although there is a high variability among participants, the mean difference of handgrip strength among temporal points have a low variability. This high variability is due to the fact that males have higher levels of handgrip strength than females [9]. The higher intensity needed for the $10 \mathrm{kHz}$ compared to the $5 \mathrm{kHz}$ intervention to achieve the same current perception was expected because higher frequencies have less resistance and less perception of the electrical current [10].

These results are in consonance with experimental animal studies which have shown a peripheral motor conduction block with frequencies between 3 and $10 \mathrm{kHz}$ [11-13]. However, only one study in humans [4] has previously applied transcutaneous HFAC at $5 \mathrm{kHz}$, with similar effects than conventional TENS on somatosensory thresholds assessment. The higher effect of the $10 \mathrm{kHz}$ current compared to the $5 \mathrm{kHz}$ confirms a frequency-dependent effect suggested by a previous study where the relationship between nerve diameter and block frequency was determined [5]. A key point to note is that the decrease of MHS evidenced during stimulation is quickly reversible when the stimulation ends, as well as the nerve conduction block observed in animals [14]. This could have relevant clinical applications to reduce specific motor activity such as blocking 
Table 1 Maximal handgrip strength measurement of each participant throughout the experimental sessions

\begin{tabular}{|c|c|c|c|c|c|c|c|c|c|c|c|c|}
\hline & \multicolumn{4}{|c|}{$\begin{array}{l}10 \mathrm{kHz} \\
\text { (Newtons) }\end{array}$} & \multicolumn{4}{|c|}{$\begin{array}{l}5 \mathrm{kHz} \\
\text { (Newtons) }\end{array}$} & \multicolumn{4}{|c|}{$\begin{array}{l}\text { Sham Stimulation } \\
\text { (Newtons) }\end{array}$} \\
\hline & 0 min & $15 \mathrm{~min}$ & $20 \mathrm{~min}$ & $30 \mathrm{~min}$ & 0 min & $15 \mathrm{~min}$ & $20 \mathrm{~min}$ & $30 \mathrm{~min}$ & $0 \min$ & $15 \mathrm{~min}$ & $20 \mathrm{~min}$ & $30 \mathrm{~min}$ \\
\hline Participant 1 & 48.7 & 43.3 & 49.5 & 49.5 & 54.8 & 45.1 & 52.2 & 50.7 & 53.9 & 54.4 & 51.5 & 51.1 \\
\hline Participant 2 & 30.6 & 25.8 & 24.7 & 27.9 & 27.5 & 29.3 & 29.0 & 29.3 & 31.8 & 31.2 & 31.4 & 32.3 \\
\hline Participant 3 & 41.0 & 35.7 & 38.1 & 39.3 & 39.3 & 38.9 & 36.1 & 40.2 & 39.4 & 36.7 & 39.8 & 41.9 \\
\hline Participant 4 & 43.7 & 35.4 & 37.0 & 39.6 & 45.5 & 37.1 & 40.7 & 41.5 & 42.0 & 45.3 & 42.1 & 41.4 \\
\hline Participant 5 & 25.6 & 18.8 & 25.2 & 23.1 & 24.1 & 22.9 & 24.0 & 24.0 & 26.6 & 27.8 & 25.7 & 25.3 \\
\hline Participant 6 & 33.8 & 32.6 & 31.2 & 33.8 & 34.5 & 36.4 & 33.3 & 30.0 & 33.4 & 35.0 & 35.3 & 33.5 \\
\hline Participant 7 & 14.9 & 15.1 & 16.2 & 15.9 & 16.0 & 16.5 & 17.4 & 17.5 & 14.7 & 17.7 & 14.3 & 15.4 \\
\hline Participant 8 & 29.3 & 25.6 & 24.8 & 27.4 & 28.1 & 28.9 & 28.1 & 30.1 & 29.6 & 27.6 & 26.8 & 27.9 \\
\hline Participant 9 & 55.3 & 52.1 & 49.5 & 50.8 & 50.3 & 52.6 & 51.4 & 52.2 & 52.2 & 53.7 & 50.8 & 50.4 \\
\hline Participant 10 & 19.1 & 14.3 & 16.4 & 19.2 & 17.2 & 16.9 & 19.3 & 18.1 & 20.6 & 19.3 & 17.3 & 18.1 \\
\hline Participant 11 & 17.2 & 10.0 & 17.3 & 19.2 & 21.5 & 16.9 & 21.0 & 22.3 & 20.3 & 21.3 & 19.5 & 18.9 \\
\hline Mean & 32.7 & 28.1 & 30.0 & 31.4 & 32.6 & 31.0 & 32.0 & 32.4 & 33.1 & 33.6 & 32.2 & 32.4 \\
\hline SD & 13.3 & 13.1 & 12.2 & 12.2 & 13.3 & 12.1 & 12.1 & 12.2 & 12.8 & 12.9 & 12.9 & 12.6 \\
\hline SEM & 4.0 & 4.0 & 3.7 & 3.7 & 4.0 & 3.7 & 3.6 & 3.7 & 3.9 & 3.9 & 3.9 & 3.8 \\
\hline
\end{tabular}

Data are expressed in Newtons. SD Standard deviation, SEM standard error of the mean

specific nerves during disabling spams or tremors. However, these effects should be studied in subjects with disorders characterized by motor hyperactivity.

\section{Study limitations}

This is a pilot study that assesses handgrip strength as an indirect indicator of motor fiber conduction. However, it is necessary to confirm these results using direct measures such as neurophysiological tests applied in both, healthy and pathological subjects. The major challenge of using neurophysiological tests during the application of HFAC is the artefact evoked by the electrical stimulation.

\section{Conclusions}

High-frequency alternating current stimulation without modulation, at a frequency of $10 \mathrm{kHz}$ applied over ulnar and median nerves of non-injured volunteers produces, during and immediately after the stimulation, a decrease of MHS when compared to HFAC at $5 \mathrm{kHz}$ and sham stimulation. This reduction in MHS could suggest a block of motor nerve activity that could be useful in subjects with neurological disorders characterized by motor hyperactivity.

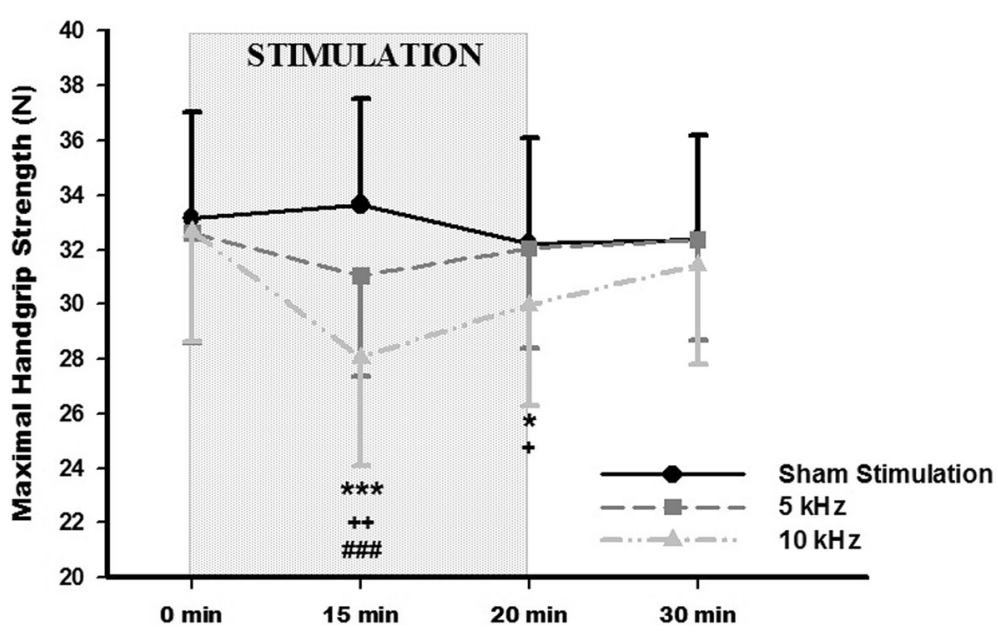

Fig. 1 Stimulation effect on maximal handgrip strength. Sham stimulation (circle), $5 \mathrm{kHz}$ (square), and $10 \mathrm{kHz}$ (triangle). Data are represented as mean and standard error. ${ }^{*}$ Indicates significantly different compared to sham stimulation $\left({ }^{* * *} p<0.001 ;{ }^{* *} p<0.01\right)$. ${ }^{+}$Indicates a significant difference compared to $5 \mathrm{kHz}$ stimulation $\left({ }^{++} p<0.01\right) .{ }^{*}$ Indicates significantly different from baseline $\left({ }^{\# \#} p<0.001\right)$ 


\section{Abbreviations}

ANOVA: Analysis of variance; HFAC: High-frequency alternating current: MSH: Maximal handgrip strength; N: Newtons; SEM: Standard error mean

\section{Funding}

This work was supported by the "Instituto de Salud Carlos III" (ref PI17/00581).

\section{Availability of data and materials}

The data collected in this study are available from the corresponding author on reasonable request.

\section{Authors' contributions}

DSM and CSM contributed in participant recruitment, data collection and drafting manuscript. JAC, JGS and JT conceiving study concept, results interpretation and supervised the whole project. All authors read and approved the final manuscript.

\section{Ethics approval and consent to participate}

The local ethical committee of the "Complejo Hospitalario de Toledo" gave approval to the study and warranted its accordance with the Declaration of Helsinki (number 158; 2-11-2017). Written informed consent was obtained from all participants prior to participation.

\section{Consent for publication}

Not applicable.

\section{Competing interests}

Avendaño-Coy, Taylor and Gómez-Soriano have a patent of a device which evokes electrical current between $10 \mathrm{kHz}$ and $50 \mathrm{kHz}$, although this device has not used in this work. The remaining authors have no conflicts of interest.

\section{Publisher's Note}

Springer Nature remains neutral with regard to jurisdictional claims in published maps and institutional affiliations.

\section{Author details}

${ }^{1}$ Sensorimotor Function Group, Hospital Nacional de Parapléjicos, 45071 Toledo, Spain. ${ }^{2}$ Toledo Physiotherapy Research Group (GIFTO), Nursing and Physiotherapy School, Castilla La Mancha University, 45071 Toledo, Spain. 3 Department of Rehabilitation Sciences, KU Leuven - University of Leuven, 3000 Leuven, Belgium.

Received: 7 May 2018 Accepted: 18 October 2018

\section{Published online: 12 November 2018}

\section{References}

1. Bhadra N, Kilgore KL. High-frequency electrical conduction block of mammalian peripheral motor nerve. Muscle Nerve. 2005;32(6):782-90.

2. Tai C, Roppolo JR, de Groat WC. Response of external urethral sphincter to high frequency biphasic electrical stimulation of pudendal nerve. J Urol. 2005;174(2):782-6.

3. Williamson RP, Andrews BJ. Localized electrical nerve blocking. IEEE Trans Biomed Eng. 2005;52(3):362-70.

4. Avendano-Coy J, et al. Effect of unmodulated $5-\mathrm{kHz}$ alternating currents versus transcutaneous electrical nerve stimulation on mechanical and thermal pain, tactile threshold, and peripheral nerve conduction: a double-blind, placebo-controlled crossover trial. Arch Phys Med Rehabil. 2017;98(5):888-95.

5. Ackermann DM, et al. Electrical conduction block in large nerves: highfrequency current delivery in the nonhuman primate. Muscle Nerve. 2011; 43(6):897-9.

6. Serrano-Munoz D, et al. Intensity matters: therapist-dependent dose of spinal transcutaneous electrical nerve stimulation. PLoS One. 2017;12(12): e0189734.

7. Aarskog $\mathrm{R}$, et al. Is mechanical pain threshold after transcutaneous electrical nerve stimulation (TENS) increased locally and unilaterally? A randomized placebo-controlled trial in healthy subjects. Physiother Res Int. 2007;12(4): 251-63.

8. Claydon LS, et al. Alternating-frequency TENS effects on experimental pain in healthy human participants: a randomized placebo-controlled trial. Clin J Pain. 2013;29(6):533-9.
9. Sisto SA, Dyson-Hudson T. Dynamometry testing in spinal cord injury. J Rehabil Res Dev. 2007:44(1):123-36

10. Beatti A, et al. Penetration and spread of interferential current in cutaneous, subcutaneous and muscle tissues. Physiotherapy. 2011;97(4):319-26.

11. Yang $G$, et al. Post-stimulation block of frog sciatic nerve by high-frequency (kHz) biphasic stimulation. Med Biol Eng Comput. 2017;55(4):585-93.

12. Kilgore $\mathrm{KL}$, Bhadra N. Nerve conduction block utilising high-frequency alternating current. Med Biol Eng Comput. 2004;42(3):394-406.

13. Ackermann DM, et al. Effect of bipolar cuff electrode design on block thresholds in high-frequency electrical neural conduction block. IEEE Trans Neural Syst Rehabil Eng. 2009;17(5):469-77.

14. Ackermann DM, et al. Conduction block of peripheral nerve using highfrequency alternating currents delivered through an intrafascicular electrode. Muscle Nerve. 2010;41(1):117-9.

\section{Ready to submit your research? Choose BMC and benefit from:}

- fast, convenient online submission

- thorough peer review by experienced researchers in your field

- rapid publication on acceptance

- support for research data, including large and complex data types

- gold Open Access which fosters wider collaboration and increased citations

- maximum visibility for your research: over $100 \mathrm{M}$ website views per year

At BMC, research is always in progress.

Learn more biomedcentral.com/submissions 